\title{
Comparative studies of vertebrate scavenger receptor class B type I: a high-density lipoprotein binding protein
}

This article was published in the following Dove Press journal:

Research and Reports in Biochemistry

16 June 2012

Number of times this article has been viewed

\author{
Roger S Holmes ${ }^{1,2}$ \\ Laura A Cox' \\ 'Department of Genetics and \\ Southwest National Primate Research \\ Center, Texas Biomedical Research \\ Institute, San Antonio, TX, USA; \\ ${ }^{2}$ School of Biomolecular and Physical \\ Sciences, Griffith University, Nathan, \\ Queensland, Australia
}

\begin{abstract}
Scavenger receptor class B type 1 protein (SCARB1) plays an essential role in cholesterol homeostasis and functions in binding high density lipoprotein cholesterol (HDL) in liver and other tissues of the body. SCARB1 also functions in lymphocyte homeostasis and in the uptake of hepatitis $\mathrm{C}$ virus (HCV) by the liver. A genetic deficiency of this protein results in autoimmune disorders and significant changes in blood cholesterol phenotype. Comparative SCARB1 amino acid sequences and structures and SCARB1 gene locations were examined using data from several vertebrate genome projects. Vertebrate SCARB1 sequences shared $50 \%-99 \%$ identity as compared with $28 \%-31 \%$ sequence identities with other CD36-like superfamily members, ie, SCARB2 and SCARB3 (also called CD36). At least eight N-glycosylation sites were conserved among most of the vertebrate SCARB1 proteins examined. Sequence alignments, key amino acid residues, and conserved predicted secondary structures were also studied, including: cytoplasmic, transmembrane, and exoplasmic sequences; conserved $\mathrm{N}$-terminal and C-terminal transmembrane glycines which participate in oligomer formation; conserved cystine disulfides and a free SH residue which participates in lipid transport; carboxyl terminal PDZbinding domain sequences (Ala507-Arg/Lys508-Leu509); and 30 conserved proline and 18 conserved glycine residues, which may contribute to short loop formation within the exoplasmic HDL-binding sequence. Vertebrate SCARB1 genes usually contained 12 coding exons. The human $S C A R B 1$ gene contained $\mathrm{CpG}$ islands, micro RNA binding sites, and several transcription factor binding sites (including PPARG) which may contribute to the high level (13.7 times the average) of gene expression. Phylogenetic analyses examined the relationships and potential evolutionary origins of the vertebrate $S C A R B 1$ gene with vertebrate $S C A R B 2$ and vertebrate and invertebrate $S C A R B 3$ (CD36) genes. These suggested that $S C A R B 1$ originated in a vertebrate ancestral genome from a gene duplication event of an ancestral invertebrate CD36 gene.
\end{abstract}

Keywords: vertebrates, amino acid sequence, SCARB1, evolution, high-density lipoprotein receptor

\section{Introduction}

Scavenger receptor class B type 1 protein (SCARB1, also called CLA1, SRB1, and CD36 L1) is one of at least three members of the type 1 thrombospondin receptor CD36 (cluster of differentiation 36) family that serves as an homo-oligomeric plasma membrane cell surface glycoprotein receptor for high-density (HDL) lipoprotein cholesterol, other phospholipid ligands, and chylomicron remnants. ${ }^{1-10}$ SCARB1 has also been implicated in the uptake of hepatitis $\mathrm{C}$ virus (HCV) in the liver ${ }^{11-14}$ and in platelet activation. ${ }^{15}$ and may also participate in the phagocytosis of apoptotic cells. ${ }^{16-18}$ SCARB2, also called lysosomal integral membrane protein 2, SRB2, and
Correspondence: Roger S Holmes School of Biomolecular and Physical Sciences, Griffith University, Nathan, Queensland 4III, Australia

Tel +6I 737357773

Email r.holmes@griffith.edu.au 
CD36 L2, is a second member of the CD36 family, predominantly integrated within lysosomal and endosomal membranes which may contribute to membrane organization and transport functions. ${ }^{19-23} \mathrm{~A}$ third member of the CD36 family, SCARB3, also called CD36, fatty acyl translocase, and glycoprotein 88 , is an integral membrane protein of many tissues of the body which plays a role in fatty acyl translocation and as a multiple ligand cell surface receptor of oxidized low-density lipoproteins, and has been implicated in several diseases, including insulin resistance, diabetes, atherosclerosis, and malaria. ${ }^{24-29}$

The gene encoding SCARB1 (SCARB1 in humans, Scarb1 in mice) is expressed at very high levels in various cells and tissues of the body, including the adrenal cortex and medulla, liver, and lymphocytes. ${ }^{1,30,31}$ Studies of Scarb1-/Scarb1 ${ }^{-}$knockout mice have shown that SCARB1 deficiency causes autoimmune disease and an accumulation of cholesterol-rich HDL in the circulation and a reduction in biliary cholesterol excretion, which supports a major role for SCARB1 in the reverse cholesterol pathway. ${ }^{18,32,33}$ Human clinical studies have also examined $S C A R B 1$ polymorphisms associated with increased plasma HDL cholesterol levels, altered platelet functions, and a reduction in cholesterol efflux from macrophages. ${ }^{34-38}$ In addition, human SCARB1 polymorphisms are associated with a number of major diseases, including type 2 diabetes, atherosclerosis, autoimmune disorders, and malarial Plasmodium liver infection. ${ }^{33,39-42}$

Structures of vertebrate $S C A R B 1$ genes have been examined, including human, ${ }^{43,44}$ mouse, ${ }^{45}$ rat, ${ }^{46} \mathrm{cow},{ }^{47}$ and salmon. ${ }^{48}$ $S C A R B 1$ genes usually contain 12 exons of DNA encoding SCARB1 sequences which undergo exon shuffling, generating several isoproteins in each case. ${ }^{31,44,49-51}$

This paper reports the predicted gene structures and amino acid sequences for several vertebrate $S C A R B 1$ genes and proteins, the secondary structures for vertebrate SCARB1 proteins, several potential sites for regulating human SCARB1 gene expression and the structural, phylogenetic, and evolutionary relationships for these genes and enzymes with those for vertebrate SCARB2 and SCARB3 (CD36) gene families.

\section{Materials and methods}

\section{Vertebrate SCARBI gene and protein identification}

BLAST (Basic Local Alignment $\underline{\text { Search }}$ Tool) studies were undertaken using web tools from the National Center for Biotechnology information site (http://blast.ncbi.nlm.nih. gov/Blast.cgi). ${ }^{52}$ Protein BLAST analyses used vertebrate
SCARB1 amino acid sequences previously described (Table 1). Non-redundant protein sequence databases for several mammalian genomes were examined using the BLASTP algorithm, including human (Homo sapiens), ${ }^{53}$ chimpanzee (Pan troglodytes) ${ }^{54}$ rhesus monkey (Macaca mulatta), ${ }^{55}$ cow (Bos taurus), ${ }^{56}$ mouse (Mus musculus), ${ }^{57}$ rat (Rattus norvegicus), ${ }^{58}$ opossum (Monodelphis domestica), ${ }^{59}$ platypus (Ornithorhynchus anatinus) ${ }^{60}$ chicken (Gallus gallus), ${ }^{61}$ lizard (Anolis carolinensis), ${ }^{62}$ frog (Xenopus tropicalis), ${ }^{63}$ and zebrafish (Danio rerio) ${ }^{64}$ This procedure produced multiple BLAST "hits" for each of the protein databases which were individually examined and retained in FASTA format, and a record was kept of the sequences for predicted mRNAs and encoded SCARB1-like proteins. These records were derived from annotated genomic sequences using the gene prediction method, ie, GNOMON and predicted sequences with high similarity scores for human SCARB1. Predicted SCARB1-like protein sequences were obtained in each case and subjected to analyses of predicted protein and gene structures.

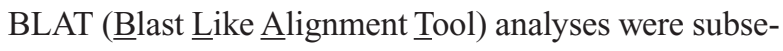
quently undertaken for each of the predicted SCARB1 amino acid sequences using the UC Santa Cruz Genome Browser ${ }^{65}$ with default settings to obtain the predicted locations for each of the vertebrate $S C A R B 1$ genes, including predicted exon boundary locations and gene sizes. BLAT analyses were similarly undertaken for other vertebrate $S C A R B 1, S C A R B 2$, and $S C A R B 3$ (CD36) genes using previously reported sequences in each case (see Table 1). Structures for human and mouse isoforms (splicing variants) were obtained using the AceView website to examine predicted gene and protein structures. ${ }^{31}$

\section{Predicted structures and properties of vertebrate SCARBI}

Predicted secondary structures for human and other vertebrate SCARB1 proteins were obtained using the PSIPRED v2.5 web site tools provided by Brunel University. ${ }^{66}$ Molecular weights, N-glycosylation sites, ${ }^{67}$ and predicted transmembrane, cytosolic, and extracellular sequences for vertebrate SCARB1 proteins were obtained using Expasy web tools (http://au.expasy.org/tools/pi_tool.html).

\section{Comparative human and mouse SCARBI gene expression}

The genome browser (http://genome.ucsc.edu) ${ }^{65}$ was used to examine GNF Expression Atlas 2 data using various expression chips for human and mouse SCARB1 genes (http:// biogps.gnf.org). ${ }^{68}$ Gene array expression "heat maps" were 
examined for comparative gene expression levels among human and mouse tissues showing high (red), intermediate (black), and low (green) expression levels.

\section{Phylogeny studies and sequence divergence}

Alignments of vertebrate SCARB1, SCARB2, and SCARB3 sequences were assembled using BioEdit v.5.0.1 and the default settings. ${ }^{69}$ Ambiguous alignment regions, including the amino and carboxyl termini, were excluded prior to phylogenetic analysis, yielding alignments of 431 residues for comparisons of vertebrate SCARB1 sequences with human, mouse, chicken, and zebrafish SCARB2 and SCARB3 sequences with the lancelet (Branchiostoma floridae) CD36 sequence (Table 1). Evolutionary distances were calculated using the Kimura option ${ }^{70}$ in TREECON. ${ }^{71}$ Phylogenetic trees were constructed from evolutionary distances using the neighborjoining method ${ }^{72}$ and rooted with the seasquirt CD36 sequence. Tree topology was reexamined by the boot-strap method (100 bootstraps were applied) of resampling, and only values that were highly significant $(\geq 95)$ are shown. ${ }^{73}$

\section{Results and discussion}

\section{Alignments of vertebrate SCARBI amino acid sequences}

The deduced amino acid sequences for pig (Sus scrofa), opossum ( $M$. domestica), platypus (O. anatinus), and frog (X. tropicalis) SCARB1 are shown in Figure 1, together with previously reported sequences for human, ${ }^{74}$ mouse, ${ }^{75}$ and cow SCARB1 (Table 1). ${ }^{47}$ Alignments of human with other vertebrate SCARB1 sequences examined were between $50 \%$ and $99 \%$ identical, suggesting that these are products of the same family of genes, whereas comparisons of sequence identities of vertebrate SCARB1 proteins with human SCARB2 and SCARB3 proteins exhibited lower levels of sequence identities of $30 \%-33 \%$ and $30 \%-32 \%$, respectively, indicating that these are members of distinct $S C A R B$ or $C D 36$-like gene families (Table 1).

The amino acid sequences for mammalian SCARB1 contained 509 residues whereas frog (X. tropicalis) SCARB1 sequences contained 505 amino acids (Figure 1). Previous studies have reported several key regions and residues for human and mouse SCARB1 proteins (human SCARB1 amino acid residues were identified in each case). These included: cytoplasmic N-terminal and C-terminal residues 2-11 and 461-509; N-terminal and C-terminal transmembrane helical regions, ie, residues $12-33$ and $441-460 ;, 846,74$ key N-terminal glycine residues (Gly15/Gly18/Gly25) which form a dimerization motif in the N-terminal transmembrane domain and participate in forming SCARB1 oligomers; ${ }^{76}$ a C-terminal PDZK1-interacting domain previously identified for the last three amino acids of SCARB1, ie, Ala-Lys-Leu; ${ }^{75}$ exoplasmic Cys384, where a free SH group plays a major role in SCARB1-mediated lipid transport; four exoplasmic disulfide bond-forming residues, ie, Cys280, Cys321, Cys323, and Cys334; ${ }^{77,78}$ and 10 exoplasmic N-glycosylation sites for human SCARB1, which have been identified or predicted for this protein (Table 2). ${ }^{79}$ One of these sites (site 1) contained a proline residue at the second position and may not function as an N-glycosylation site due to proline-induced inaccessibility. ${ }^{67}$ Eight of these sites were predominantly retained among the 19 vertebrate SCARB1 sequences examined (sites 2-3 and 6-12 in Table 2), whereas rat and mouse SCARB1 sequences contained an additional $\mathrm{N}$-glycosylation site at 116 Asn-117 Arg-118Ser, and chicken, lizard, and salmon SCARB1 sequences contained a further site at 125 Asn-126Gly-127Thr (Figure 1, Table 2). Given the sequence conservation observed for these residues among the vertebrate SCARB1 sequences examined, it is apparent that they are essential for the structure and function of a glycoprotein. The multiple N-glycosylation sites observed for vertebrate SCARB1 sequences support a major role for glycan residues exposed on the external surface of plasma membranes in the performance of SCARB1 functions in binding various lipoproteins, including HDL, and in cholesterol transfer, as part of the reverse cholesterol transport role proposed for SCARB1. ${ }^{79}$

\section{Conserved glycines in $\mathrm{N}$-terminal oligomerization domain of the transmembrane sequence}

The N-terminal region for vertebrate SCARB1 sequences (residues 1-42 for human SCARB1) contained cytoplasmic (residues 2-11) and transmembrane (residues 12-33) motifs which underwent changes in amino acid sequence but retained the predicted cytoplasmic and transmembrane properties in each case (Figure 1, Supplementary Figure 1). Vertebrate $\mathrm{N}$-terminal transmembrane sequences in particular were predominantly conserved, especially for Gly15, Gly18, and Gly25 SCARB1 residues, which were fully conserved among all mammalian and frog SCARB1 sequences examined (Figure 1, Supplementary Figure 1). However, other lower vertebrate SCARB1 sequences, such as lizard and zebrafish SCARB1 sequences, contained a replacement at the Gly15 position (Ala15 and Leu12, respectively, data not shown). Additional glycine residues were observed in this region for some vertebrate SCARB1 sequences, including consecutive 
Table I Vertebrate SCARBI, SCARB2, and SCARB3 genes and proteins

\begin{tabular}{|c|c|c|c|c|c|c|}
\hline SCARB I gene & Species & $\begin{array}{l}\text { RefSeq ID } \\
\text { 'EnsembI/NCBI }\end{array}$ & $\begin{array}{l}\text { GenBank } \\
\text { ID }\end{array}$ & $\begin{array}{l}\text { UNIPROT } \\
\text { ID }\end{array}$ & $\begin{array}{l}\text { Amino } \\
\text { acids }\end{array}$ & $\begin{array}{l}\text { Chromosome } \\
\text { location }\end{array}$ \\
\hline Human & Homo sapiens & NM_00505 & BC022087 & Q8WVT0 & 509 & $12: 125,267,232-125,348,266$ \\
\hline Chimpanzee & Pan troglodytes & 'XP_0033I4063.I & na & na & 509 & $12: 125,656,282-125,738,482$ \\
\hline Gorilla & Gorilla gorilla & 'ENSGGOP6367 & na & G3QUG5 & 509 & $|2:| 24,7|8,744-| 24,804,938$ \\
\hline Gibbon & Nomascus leucogenys & 'XP_003276298.I & na & GIQQ5I & 509 & GL39739I:I,704,805-I,787,403 \\
\hline Rhesus & Macaca mulatta & 'XP_00II0I8I2.I & na & F7GMT2 & 509 & $|I:| 26,096,068-|26| 76,,85 \mid$ \\
\hline Mouse & Mus musculus & NM_00I205082.I & BC004656 & Q61009 & 509 & $5:|25,76|, 478-|25,82|, 252$ \\
\hline Rat & Rattus norvegicus & NM_03I54I & BC076504 & P97943 & 509 & $12: 32,390,385-32,453,972$ \\
\hline Guinea Pig & Cavia porcellus & 'XP_00346I673.I & na & na & 509 & $|78:|, 245,087-|, 276,8| \mid$ \\
\hline Cow & Bos taurus & NM_I74597 & BTI9968 & OI8824 & 509 & $|7: 53| ,8|, 037-53,267,9| \mid$ \\
\hline Dog & Canis familaris & 'ENSCAFPI 0357 & na & na & 509 & $26: 8,098,793-8,128,586$ \\
\hline Pig & Sus scrofa & NM_213967.I & AF467889 & Q8SQCI & 509 & $|4: 28,30|, 496-28,388,350$ \\
\hline Rabbit & Oryctolagus cuniculus & NM_00I082788.I & AY283277.I & na & 509 & Un0166:48I-I8,522 \\
\hline Opossum & Monodelphis domestica & 'XP_00I379299 & na & F7E0V5 & 509 & $3: 475,428,162-475,518,702$ \\
\hline Platypus & Ornithorhynchus anatinus & 'XP_00I508I98 & na & F7F3F3 & 509 & $196: 2,257,972-2,3 \mid 3,254$ \\
\hline Chicken & Gallus gallus & 'XP_4I5I06 & na & na & 503 & I5:4,543,054-4,558,954 \\
\hline Lizard & Anolis carolinensis & 'ENSACATI4873 & na & na & 502 & LGb:I,343,0II-I,368,333 \\
\hline Frog & Xenopus tropicalis & 'XP_002935333 & na & na & 505 & GLI 72777:533,463-579,626 \\
\hline Zebrafish & Danio rerio & NM_198121 & BC0445I6 & E7FB50 & 496 & ||$: 2|, 526,5| 3-2 \mid, 572,478$ \\
\hline Salmon & Salmo salar & NM_00I204894.I & HQ403588 & E9N3T5 & 486 & na \\
\hline \multicolumn{7}{|l|}{ SCARB2 gene } \\
\hline Human & Homo sapiens & NM_005506 & ВТ006939 & Q53Y63 & 478 & $4: 77,084,378-77,134,696$ \\
\hline Mouse & Mus musculus & NM_007644 & BC029073 & 035114 & 478 & $5: 92,875,330-92,934,334$ \\
\hline Chicken & Gallus gallus & 'XP_42093.I & BX931548 & na & 481 & $4: 5 I, 4 \mid I, 268-5 I, 429,620$ \\
\hline Zebrafish & Danio rerio & NM_I73259.I & $\mathrm{BCl} 62407$ & Q8JQR8 & 531 & 5: 63,942,096-63,955,449 \\
\hline \multicolumn{7}{|l|}{ SCARB3 gene } \\
\hline Human & Homo sapiens & NM_00I00I547 & BC008406 & PI667I & 472 & $7: 80,275,645-80,303,732$ \\
\hline Mouse & Mus musculus & NM_00II59555.I & $\mathrm{BC} 010262$ & Q08857 & 472 & $5:|7,29|, 543-|7,334,7| 2$ \\
\hline Chicken & Gallus gallus & 'ENSGALG8439 & AJ719746 & FINER9 & 471 & $|:| 2,077,308-|2| 107,,4 \mid 5$ \\
\hline Zebrafish & Danio rerio & NP_001002363.I & BC076048 & Q6DHC7 & 465 & $4: 21,594,449-21,606,961$ \\
\hline \multicolumn{7}{|l|}{ CD36 gene } \\
\hline Lancelet & $\begin{array}{l}\text { Branchiostoma } \\
\text { floridae }\end{array}$ & 'XP_002609I78.I & na & na & 480 & Un:534,334,234-534,343,082 \\
\hline Sea squirt & Ciona intestinalis & 'XP_002I270I5.I & na & na & 523 & $09 p: 2,872,362-2,873,903$ \\
\hline Nematode & $\begin{array}{l}\text { Caenorhabditis } \\
\text { elegans }\end{array}$ & NM_067224 & na & Q9XTT3 & 534 & III:I2,453,609-I2,456,726 \\
\hline
\end{tabular}

Notes: RefSeq: reference amino acid sequence; 'predicted Ensembl amino acid sequence; na, not available; GenBank IDs are derived from National Center for Biotechnology Information (http://www.ncbi.nlm.nih.gov/genbank/); Ensembl ID was derived from the Ensembl genome database (http://www.ensembl.org); UNIPROT refers to UniprotKB/ Swiss-Prot IDs for individual SCARB-like proteins (http://kr.expasy.org); *partial gene size only; Un refers to unknown chromosome; bps refers to base pairs of nucleotide sequences.

Abbreviation: SCARB, scavenger receptor class B.

glycines for opossum SCARB1 (residues 25 and 26, Figure 1) and for chicken (residues 23 and 24) and zebrafish (residues 15 and 16) SCARB1 sequences (sequences not shown). Sitedirected mutagenesis studies have demonstrated key roles for the Gly15-(X) -Gly18-(X) -Gly25 motif within the N-terminus transmembrane sequence, by facilitating oligomerization and selective lipid uptake by SCARB1, particularly for the Gly 18 and Gly 25 residues. ${ }^{76} \mathrm{~A}$ conserved glycine residue was also observed for the mammalian and frog C-terminal transmembrane sequences (human SCARB1 Gly451, Figure 1, Supplementary Figure 1), but it is not known whether or not this glycine has a similar role to that of the conserved $\mathrm{N}$-terminal transmembrane glycine residues.

\section{Conservation of cytoplasmic C-terminal PDZKI-interacting domain}

The cytoplasmic C-terminal region of SCARB1, particularly the last three amino acids of mouse SCARB1, ie, Ala507Lys508-Leu509, has been shown to interact with a PDZ domain-containing protein (PDZK1) which has been suggested to be responsible for the cell surface expression of this protein. ${ }^{75,80,81} \mathrm{PDZ}$ domains have been previously shown 


\begin{tabular}{|c|c|c|c|c|c|c|}
\hline $\begin{array}{l}\text { Coding exons } \\
\text { (strand) }\end{array}$ & Gene size bps & Subunit MW & $\begin{array}{l}\text { Gene expression } \\
\text { Level }\end{array}$ & $\begin{array}{l}\text { \% Identity with } \\
\text { human SCARB I }\end{array}$ & $\begin{array}{l}\% \text { identity with } \\
\text { human SCARB2 }\end{array}$ & $\begin{array}{l}\% \text { identity with } \\
\text { human SCARB3 }\end{array}$ \\
\hline $12(-v e)$ & 81,035 & 56,973 & 13.7 & 100 & 29 & 31 \\
\hline $12(-v e)$ & 82,201 & 56,973 & na & 100 & 29 & 29 \\
\hline $12(-v e)$ & 86,195 & 57,034 & na & 99 & 29 & 31 \\
\hline $12(-v e)$ & 82,599 & 57,029 & na & 99 & 29 & 31 \\
\hline $12(-v e)$ & 80,784 & 57,046 & na & 97 & 29 & 30 \\
\hline $12(-v e)$ & 63,985 & 56,754 & 5.1 & 79 & 29 & 29 \\
\hline $12(+v e)$ & 63,588 & 56,973 & 0.5 & 78 & 28 & 28 \\
\hline $12(+v e)$ & 31,725 & 56,969 & na & 75 & 29 & 30 \\
\hline $12(+v e)$ & 86,875 & 57,610 & na & 83 & 29 & 29 \\
\hline II (+ve) & 29,794 & 57,149 & na & 79 & 28 & 27 \\
\hline $12(+v e)$ & 86,855 & 57,514 & na & 87 & 29 & 28 \\
\hline $12(-v e)$ & $18,042^{*}$ & 57,080 & na & 80 & 28 & 28 \\
\hline $12(+v e)$ & 90,541 & 57,682 & na & 70 & 28 & 28 \\
\hline $12(-v e)$ & 55,283 & 57,839 & na & 73 & 28 & 28 \\
\hline $12(+v e)$ & $|5,90|$ & 55,918 & na & 57 & 28 & 31 \\
\hline 12 (+ve) & 25,323 & 56,147 & na & 58 & 30 & 28 \\
\hline $12(-v e)$ & 46,164 & 57,240 & na & 54 & 28 & 30 \\
\hline $12(-v e)$ & 45,684 & 55,742 & na & 51 & 28 & 30 \\
\hline na & na & 55,097 & na & 50 & 28 & 30 \\
\hline $12(-v e)$ & 50,316 & 54,290 & 3.2 & 29 & 100 & 30 \\
\hline $12(-v e)$ & 59,005 & 54,044 & 3.6 & 29 & 85 & 31 \\
\hline 12 (+ve) & 18,353 & 53,907 & na & 30 & 59 & 33 \\
\hline I3 (+ve) & 13,354 & 60,234 & na & 31 & 43 & 33 \\
\hline 12 (+ve) & 72,231 & 53,053 & 5.7 & 31 & 30 & 100 \\
\hline $12(-v e)$ & 43,170 & 52,698 & 4.2 & 30 & 31 & 83 \\
\hline $12(-v e)$ & 30,108 & 52,624 & na & 30 & 32 & 61 \\
\hline $12(-v e)$ & 12,513 & 51,590 & na & 31 & 31 & 53 \\
\hline $12(+\mathrm{ve})$ & 8,849 & 54,141 & na & 34 & 35 & 35 \\
\hline I (-ve) & 1,542 & 58009.00 & na & 26 & 33 & 31 \\
\hline 8 (+ve) & 3,118 & 60,182 & 4.6 & 21 & 26 & 24 \\
\hline
\end{tabular}

to be abundant protein interaction motifs which function in regulating biological processes such as transport (in this case, lipid transport), ion channel signaling, and other signal transduction systems. ${ }^{82,83}$ Comparisons of mammalian SCARB1 cytoplasmic C-terminal sequences (Supplementary Figure 1) support a high level of conservation for the last three amino acids, with a consensus sequence of Ala507-Lys/Arg508Leu509 being maintained. This conservation extends further into the protein as follows: Gly501-Thr, Ser or Ala502Val503-Leu504-Gln505-Glu506, which may also contribute to PDZK1 binding.

\section{Conserved cysteine residues within the exoplasmic domain}

Five cysteine residues of the mammalian and frog SCARB1 exoplasmic sequences (residues 34-440 for human SCARB1) were conserved among the proteins examined, of which four participate in disulfide bridge formation (cys281, cys321, cys323, and cys334), and the fifth (cys384) plays an essential role (via the free $\mathrm{SH}$ group) in lipid transport. ${ }^{77}$ A sixth cysteine residue (cys251) is also conserved among the mammalian SCARB1 sequences examined and contains a free thiol group, although site-directed mutagenesis studies have 


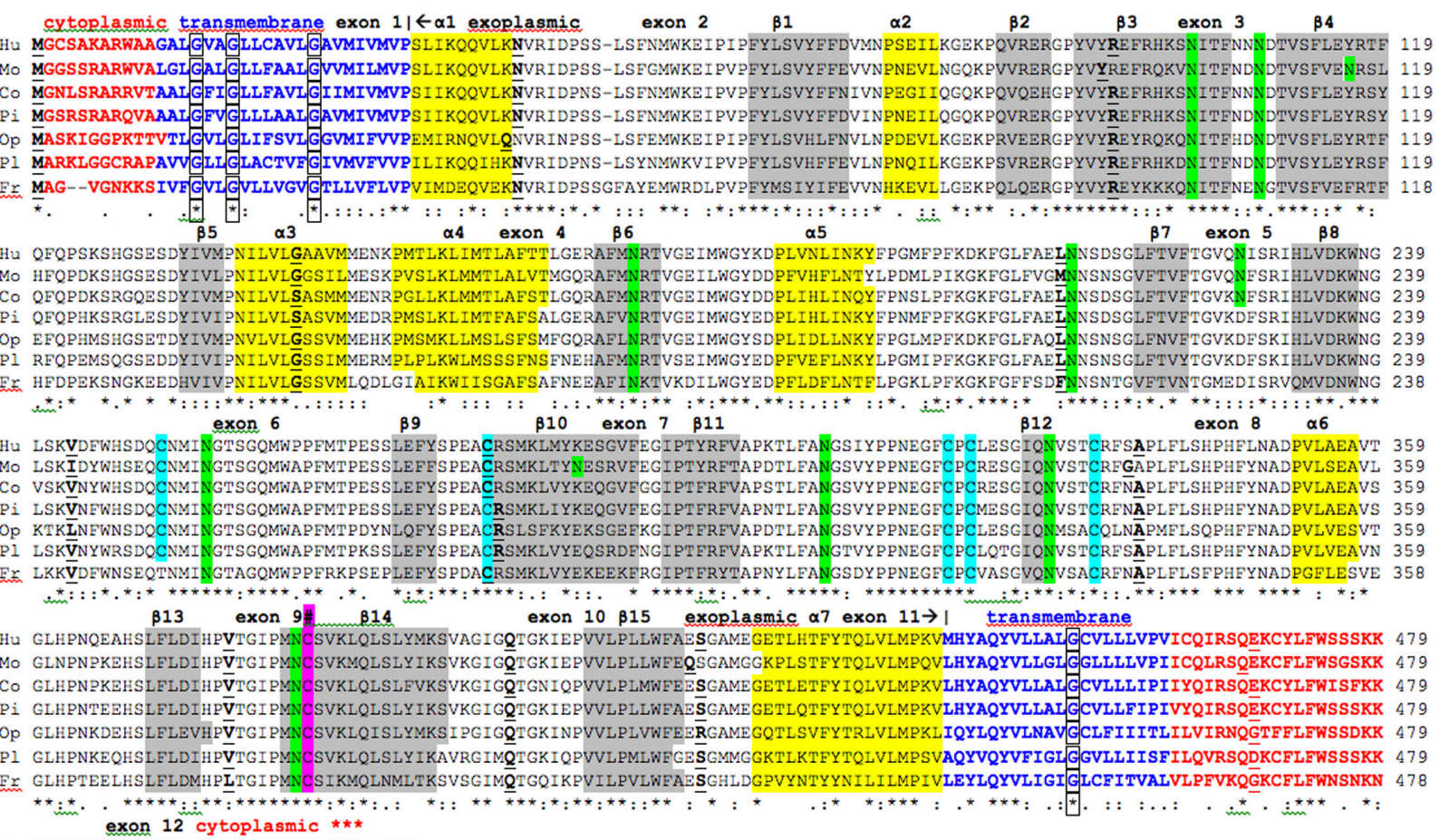

Hu MGCSAKARWAAGALGVAGLLCAVLGAVMIVMVPSLIKQQVLKNVRIDPSS-LSFNMWKEIPI PFYLSVYFFDVMNPSEILKGEKPQVRERGPYVYREFRHKSNITFNNNDTVSFLEYRTF 119

Mo MGGSSRARWVALGLGALGLLFAALGVVMILMVPSLI KQQVLKNVRIDPSS-LSFGMWKEI PVPFYLSVYFFEVVNPNEVLNGQKPVVRERGPYVYREFRQKVNITFNDNDTVSFVENRSI 119

Co MGNLSRARRVTAALGEI GLLFAVI G I IMIVMVPSI IKOOVL KNVRIDPNS-LSFNMWKEI PVPFYLSVYFFNIVNPEGIIOGOKPOVOEHGPYVYREFRHKSNITENNNDTVSFLEYRSY 119

Pi MGSRSRARQVAAALG GV GLLLAALGAVMIVMVPSIIKQQVLKN

Op MASKIGGPKTTVTLGVLGLIFSVLGGVMIFVVPEMIRNQVLQNVRINPSS-LSFEMWKEI PI PFYLSVHLFNVLNPDEVLKGEKPRVEERGPYVYREYRQKQNITEHDNDTVSFLEYRTF 119

P1 MARKLGGCRAPAVVGLIGLACTVF GIVMVVVPILIKQQIHKNVRIDPNS-LSYNMWKVI PVPFYLSVHFFEVLNPNQILKGEKPSVRERGPYVY $\bar{R} E$ FRHKDNITFNDNDTVSYLEYRSF 119

I. MAG--VGNKKSIVFGVLGVLLVGVGTLLVFLVPVIMDEQVEKNVRIDPSSGFAYEMWRDL PVPFYMS IY I FEVVNHKEVLLGEKPQLQERGPYVYREYKKKQNITFNENGTVSFVEFRTF 11

Op EFQPHMS

P1 RFQPEMSOGSEDDYIVIPNILVLGSSIMMERMPLPLKWLMSSSFNSFNEHAFMNRTVSEIMWGYEDPFVEFLNKYLPGMIPFKGKFGLFAEINNSNSGLFTVYTGVKDFSKIHLVDKWNG 239

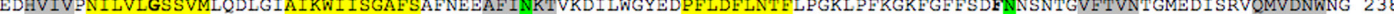

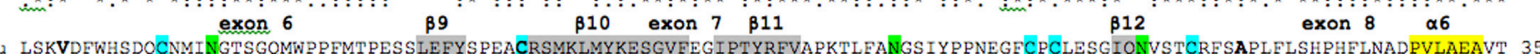

Mo LSKIDDYHSEOCNMINGTSGQMWAPFMTPESSLEFFSPEA

Co VSKV̄NYWHSDOCNMINGTSGOMVIAPFTPESSLEFYSPEACRSMKLVYKEOGVFGGIPT FRFVAPSTL FANGSVYPPNEGFCPCRESGIONVSTCRENAPLFLSHPHFYNADPVLAEAVS 359

Pi LSKV̄NFWHSDQCNMINGTSGQMWAPFMTPESSLEFYSPEACRSMKLIYKEQGVFEGIPTFRFVAPNTLFANGSVYPPNEGECPCMESGIQNVSTCRENÄPLFLSHPHFYNADPVLAEAVS 359

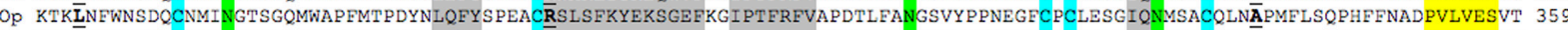

P1 LSKV̄NYWRSDQCNMINGTSGQMWAPFMTPKSSLEFYSPEACR SMKLVYEQSRDFNGIPT FRFVAPKTLFANGTVYPPNEGECPCLQTGIONVSTCRFSÄPLFLSHPHFYNADPVLVEAVN 359

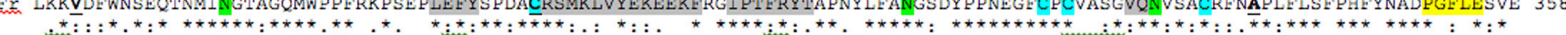

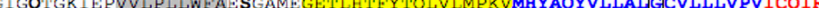

MO GLNPNPKSHSLFLDIHPVTGIPMNCSVKMOLSLYIKSVKGIGOTGKIEPVVLPLLWEEOSGAMGGKPLSTEYTOLVLMPOVLHYAOYVLIGIGGLLLLVPIICOLRSOEKCELFWSGSKK 479

Co GLHPNPKEHSLFLDIHPV TGI PMNCSVKLQLSLFVKSVKGIGQTGNIQPVVLPLMWFE SGMMEGETLETFYIQLVLMPKVLHYAQYVLIALGCVLLLIPIIYQIRSQEKCYLFWISFKK 479

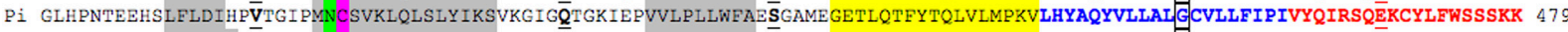

P1

Fr GLHPTEELHSLFLDMHPLTGI PMNCSI KMOLNMLTKSVSGIMQTGQIKPVILPVLWFAESGHLDGPVYNTYYNILILMPIVLEYLQYVLIGI GLCFITVALVLPFVKQGKCFLFWNSNKN 478

exon 12 cytoplasmic ***

HU GSKDKEAIQAYSESLMTSAPKGSVIQEAKL 509

MO GSQDKEAIQAYSESLMSPAAKGTVLQEAKL 509

CO GSKDKEAVQAYSEFLMTSAPKGTVLQEARL 509

Pi GSKDKEAIQAYSESLMTPAPKGTVLQEARL 509

Op VSKNSEAIOSYSESLMTPAPNGTVLOEARL 509

P1 GPKNKEAIQVYSETLMTSTHNGTVLQEARL 509

F. VDESQE-FKTQKEKLT--APNGIVLLEARL 505

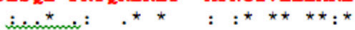

Figure I Amino acid sequence alignments for vertebrate SCARBI sequences.

Notes: See Table I for sources of SCARBI sequences. *Identical residues for SCARBI subunits; similar alternate residues; dissimilar alternate residues; predicted cytoplasmic residues are shown in red; predicted transmembrane residues are shown in blue; $\mathrm{N}$-glycosylated and potential $\mathrm{N}$-glycosylated Asn sites are shown in green; free SH Cys involved in lipid transfer is shown in pink; predicted disulfide bond Cys residues are shown in blue; predicted $\alpha$-helices for vertebrate SCARBI are shown in yellow and numbered in sequence from the start of the predicted exoplasmic domain; predicted $\beta$-sheets are shown in gray and also numbered in sequence; bold underlined font shows residues corresponding to known or predicted exon start sites; exon numbers refer to human SCARBI gene exons. **Final three C-terminal residues which bind a PDZ domain-containing protein (PDZKI); G residues are conserved glycines in the $\mathrm{N}$-terminal oligomerization domain of the transmembrane sequence. ${ }^{76}$

Abbreviations: Hu, human; Mo, mouse; Co, cow; Pi, pig; Op, opossum; PI, platypus; Fr, frog; SCARBI, scavenger receptor class B type I protein

demonstrated no significant involvement of this exoplasmic $\mathrm{SH}$ group in lipid transfer activity. ${ }^{77}$ Moreover, the Cys251 residue has been substituted in the frog SCARB1 sequence by threonine, supporting the view that it is not an essential amino acid for vertebrate SCARB1 at this position (Figure 1).

\section{Predicted secondary structures for vertebrate SCARBI}

Predicted secondary structures for mammalian and frog SCARB1 sequences were examined (Figure 1), particularly for the exoplasmic sequences. $\alpha$-helix and $\beta$-sheet structures were similar in each case, with an $\alpha$-helix extending beyond the $\mathrm{N}$-terminal and $\mathrm{C}$-terminal transmembrane regions: $\alpha 1$ and $\alpha 7$. A consistent sequence of predicted secondary structure was observed for each of mammalian and frog SCARB1 sequences: $\mathrm{N}$-terminal cytoplasmic sequence--N-terminal transmembrane sequence-- $\alpha 1$-- $\beta 1--\alpha 2--\beta 2--\beta 3--\beta 4--\beta 5--\alpha 3--\alpha 4--\beta 6--\alpha 5--$ $\beta 7--\beta 8--\beta 9--\beta 10--\beta 11--\beta 12--\alpha 6--\beta 13--\beta 14--\beta 15--\alpha 7--C-$ terminal transmembrane sequence--C-terminal cytoplasmic sequence. Further description of the secondary and tertiary structures for SCARB1 must await the three-dimensional structure for this protein, particularly for the exoplasmic region which directly binds HDL and participates in reverse cholesterol transport.

\section{Conserved proline and glycine residues within the SCARBI exoplasmic domain}

Figure 2 shows the alignment of 15 vertebrate SCARB1 amino acid sequences for the exoplasmic domain, with colors depicting the properties of individual amino acids and the strong conservation observed for these protein sequences. In addition to the key vertebrate SCARB1 amino acids detailed previously, others are also conserved, including 30 proline residues. Prolines play a major role in protein folding and protein-protein interactions involving the cyclic pyrrolidine 


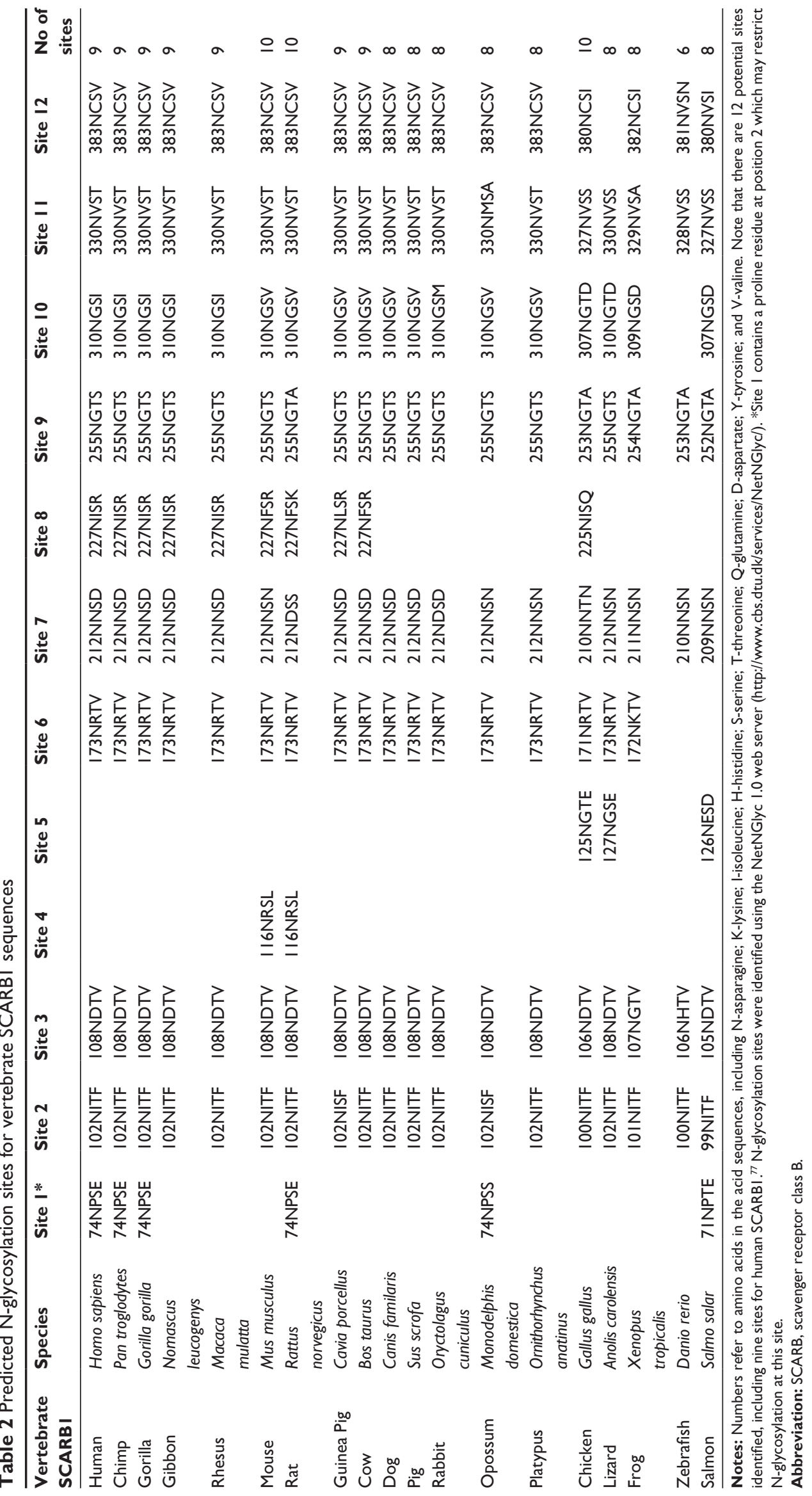



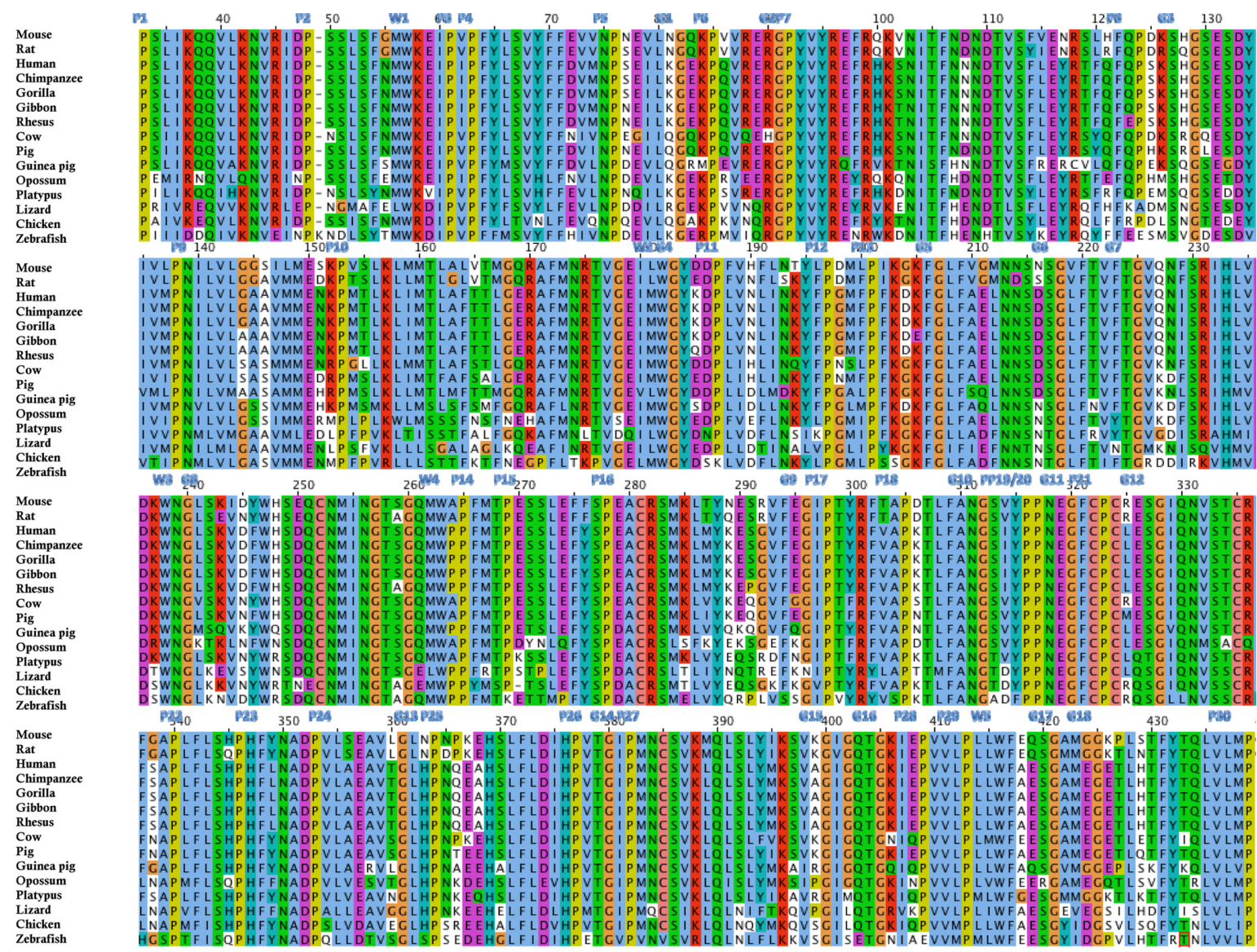

Figure 2 Amino acid sequence alignments for vertebrate SCARBI exoplasmic sequences.

Notes: Amino acids are color-coded: yellow for proline (P); S (serine); green for hydrophilic amino acids, S (serine), Q (glutamine), N (asparagine), and T (threonine); brown for glycine (G); light blue for hydrophobic amino acids, L (leucine), I (isoleucine), V (valine), M (methionine), and W (tryptophan); dark blue for amino acids, T (tyrosine) and $\mathrm{H}$ (histidine); purple for acidic amino acids, $\mathrm{E}$ (glutamate) and $\mathrm{D}$ (aspartate); and red for basic amino acids, $\mathrm{K}$ (lysine) and $\mathrm{R}$ (arginine); conserved prolines ( $\mathrm{P}$ ) numbered PI-P30; conserved glycines numbered GI-GI8; and conserved tryptophans numbered from WI-W5.

Abbreviation: SCARBI, scavenger receptor class B type I protein.

amino acid side chain, which may introduce turns (or kinks) in the polypeptide chain as well as having destabilizing effects on $\alpha$-helix and $\beta$-strand conformations. ${ }^{84}$ In addition, the presence of sequential prolines within a protein sequence may confer further restriction in folding conformation and create a distinctive structure, such as that reported for the mammalian $\mathrm{Na}^{+} / \mathrm{H}^{+}$exchanger, which plays a major role in cation transport. ${ }^{85}$ Sequential prolines (Pro317-Pro318) were conserved for all vertebrate SCARB1 sequences examined and may confer a distinctive conformation in this region, supporting the lipid transfer functions for this protein (Figure 2). Moreover, regions of water-exposed proteins with high levels of proline residues are often sites for protein-protein interactions ${ }^{86}$ and these residues may play essential roles in the binding of HDL and other lipoproteins by the exoplasmic region of SCARB1.

Figure 2 also shows conservation of 18 glycine residues for these vertebrate SCARB1 exoplasmic domains which, due to their small size, may be essential for static turns, bends, or close packing in the domain, or required for conformational dynamics during HDL receptor on-off switching, as in the case of the aspartate receptor protein. ${ }^{87}$ Both proline and glycine residues are frequently found in turn and loop structures of proteins, and usually influence short loop formation within proteins containing $2-10$ amino acids ${ }^{88}$ Evidence for these short loop structures within SCARB1 exoplasmic sequences was evident from the predicted secondary structures for vertebrate SCARB1 (see Figure 1) with proline and/or glycine residues found at the start of the following structures: $\alpha 1$ (Pro33), $\beta 1$ (Pro62), $\alpha 2$ (Pro75), $\beta 2$ (Pro84), $\beta 3$ (Gly90-Pro91), $\alpha 3$ (Pro136), $\alpha 4$ (Pro152), $\alpha 5$ (Pro186), $\beta 7$ (Gly206), $\beta 10$ (Pro277), $\beta 11$ (296Gly, 298Pro), $\beta 12$ (Gly327), $\alpha 6$ (Pro352), $\beta 14$ (Gly379, Pro381), $\beta 15$ (Pro408), and $\alpha 7$ (Gly424). Moreover, conserved SCARB1 sequential proline residues (Pro315-Pro316) are located in a region with no predicted secondary structure (between $\beta 11$ and $\beta 12$ ) but 
with disulfide bonds present, ${ }^{77}$ which suggests that this is a region of conformational significance for SCARB1.

\section{Alignments of mouse SCARBI, SCARB2, and SCARB3 (CD36) amino acid sequences}

The amino acid sequences for mouse SCARB1, SCARB2, and SCARB3 (see Table 1) are aligned in Figure 3. The sequences were $30 \%-33 \%$ identical and showed similarities in several key features and residues, including: cytoplasmic N-terminal and $\mathrm{C}$-terminal residues; $\mathrm{N}$-terminal and C-terminal transmembrane helical regions; exoplasmic disulfide bond forming residues, previously identified for mouse SCARB3 (CD36): Cys243, Cys272, Cys311, Cys313, Cys322, and Cys $333 ;{ }^{77}$ several predicted N-glycosylation sites for mouse SCARB1 (11 sites), SCARB2 (11 sites), and SCARB3 (7 sites), of which two are shared between these sequences (N-glycosylation sites 7 and 9 (Table 2)); and similar predicted secondary structures previously identified for SCARB1 (Figure 1). The free SH group Cys384 residue, which plays a major role in SCARB1-mediated lipid transport, ${ }^{77}$ was unique for SCARB1, being replaced by other residues for the corresponding SCARB2 and SCARB3 proteins. N-terminal transmembrane glycine residues, which play a role in the formation of SCARB1 oligomers, ${ }^{76}$ were also observed for the corresponding mouse SCARB3 (CD36) sequence, although only one of these glycines (Gly10) was retained for the mouse SCARB2 sequence. These results suggest that mouse SCARB1, SCARB2, and SCARB3 proteins share several important properties, features, and conserved residues, including being membrane-bound with cytoplasmic and transmembrane regions, and have similar secondary structures, but are sufficiently different to serve distinct functions.

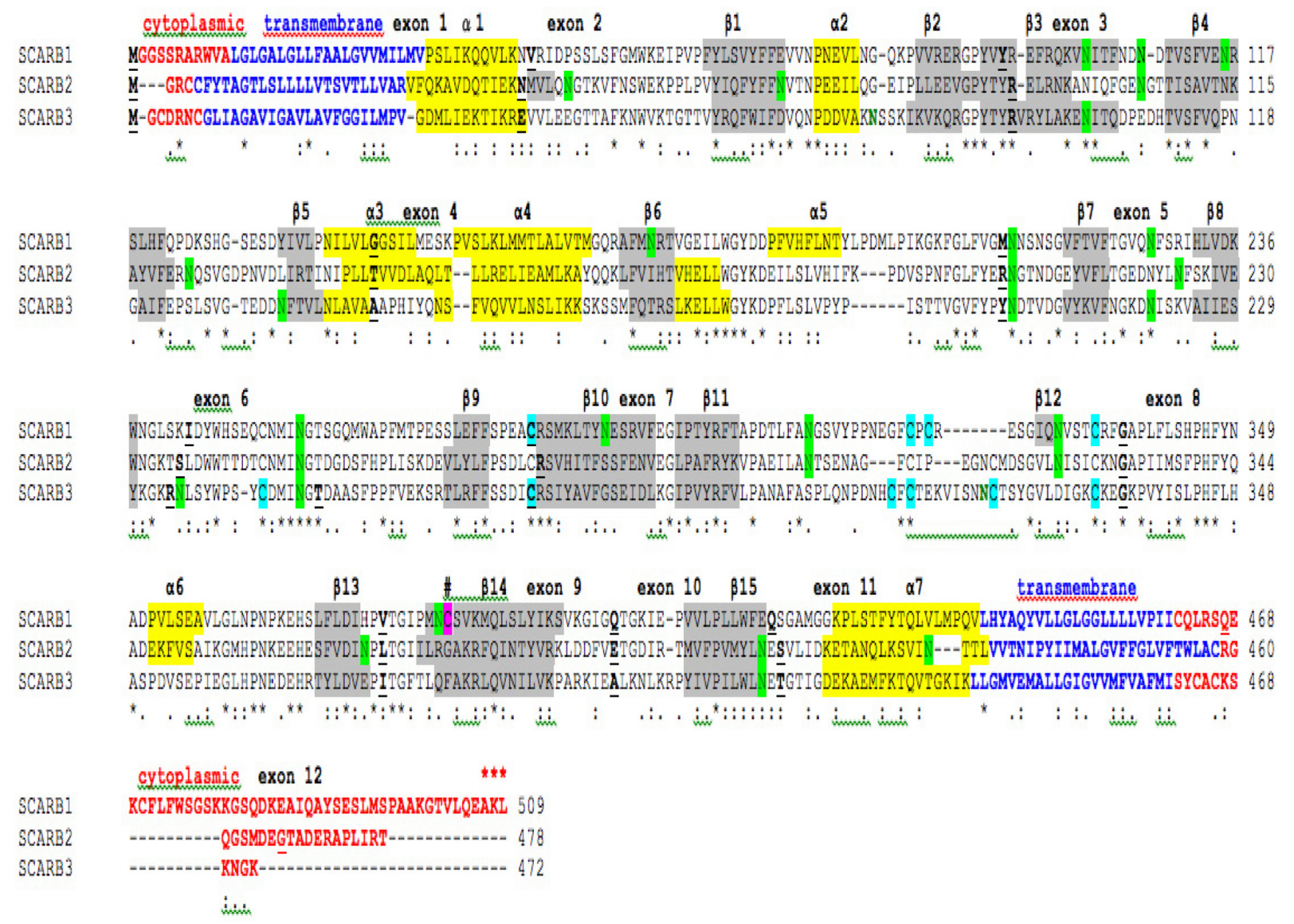

Figure 3 Amino acid sequence alignments for mouse SCARBI, SCARB2, and SCARB3 (CD36) sequences.

Notes: See Table I for sources of mouse SCARBI, SCARB2, and SCARB3 (CD36) sequences. *Identical residues for SCARBI subunits; similar alternate residues; dissimilar alternate residues; predicted cytoplasmic residues are shown in red; predicted transmembrane residues are shown in blue; $\mathrm{N}$-glycosylated and potential $\mathrm{N}$-glycosylated Asn sites are in green; free SH Cys involved in lipid transfer is shown in pink; predicted disulfide bond Cys residues are shown in blue; predicted $\alpha$-helices for vertebrate SCARBI are in shaded yellow and numbered in sequence from the start of the predicted exoplasmic domain; predicted $\beta$-sheets are in shaded gray and also numbered in sequence; bold underlined font shows residues corresponding to known or predicted exon start sites; exon numbers are shown; ***Final three C-terminal residues which bind a PDZ domain-containing protein (PDZKI) for mouse SCARBI.

Abbreviation: SCARB, scavenger receptor class $B$. 


\section{Gene locations and exonic structures for vertebrate SCARBI genes}

Table 1 summarizes the predicted locations for vertebrate SCARB1 genes based upon BLAT interrogations of several vertebrate genomes using the reported sequences for human, ${ }^{43,44}$ mouse, ${ }^{45}$ rat ${ }^{46}$ cow, ${ }^{47}$ and salmon ${ }^{48}$ and the predicted sequences for other vertebrate $S C A R B 1$ genes and the UC Santa Cruz genome browser. ${ }^{65}$ The predicted vertebrate $S C A R B 1$ genes were transcribed on either the negative strand (primate, mouse, rabbit, platypus, frog, and zebrafish genomes) or the positive strand (rat, guinea pig, cow, dog, pig, opossum, chicken, and lizard genomes). Figure 1 summarizes the predicted exonic start sites for human, mouse, cow, opossum, platypus, and frog SCARB1 genes, with each having 12 coding exons in identical or similar positions to those predicted for the human SCARB1 gene. ${ }^{43,44}$

Figure 4 shows the predicted structures of mRNAs for the three major human SCARBI transcripts and the major
Scarb1 transcript. ${ }^{31}$ The human transcripts were 2.6-2.7 kilobases in length, with 12 (isoforms a and c) or 13 (isoform $\mathrm{b}$ ) introns present for these $S C A R B 1 \mathrm{mRNA}$ transcripts, and in each case, an extended $3^{\prime}$-untranslated region was observed. The human SCARB1 genome sequence contained several predicted transcription factor binding sites, three microRNA binding sites (miR-125/351, miR-223, and miR145) located in the $3^{\prime}$-untranslated region and three $\mathrm{CpG}$ islands (CpG78, CpG24, and CpG27), of which CpG78 is located in the $5^{\prime}$-untranslated promoter region of human SCARB1 on chromosome 12. Mouse Scarb1 also contains a $\mathrm{CpG}$ island within the gene promoter $(\mathrm{CpG} 33)$ as well as two of the human predicted microRNA target sites (miR145 and miR125/351) within the mouse Scarb1 3'-untranslated region. The SCARB1 CpG islands residing proximate to the promoter may contribute to the very high level of gene expression (13.7 times for human SCARB1 and 5.1 times the average gene expression for mouse Scarb1) $)^{31}$ and may be

Human SCARB1 $5^{\prime} \rightarrow 3^{\prime}$ 'chromosome 12:123,930,960-123,828,122 size $=102.84 \mathrm{~kb}$

13.7 times average gene expression level

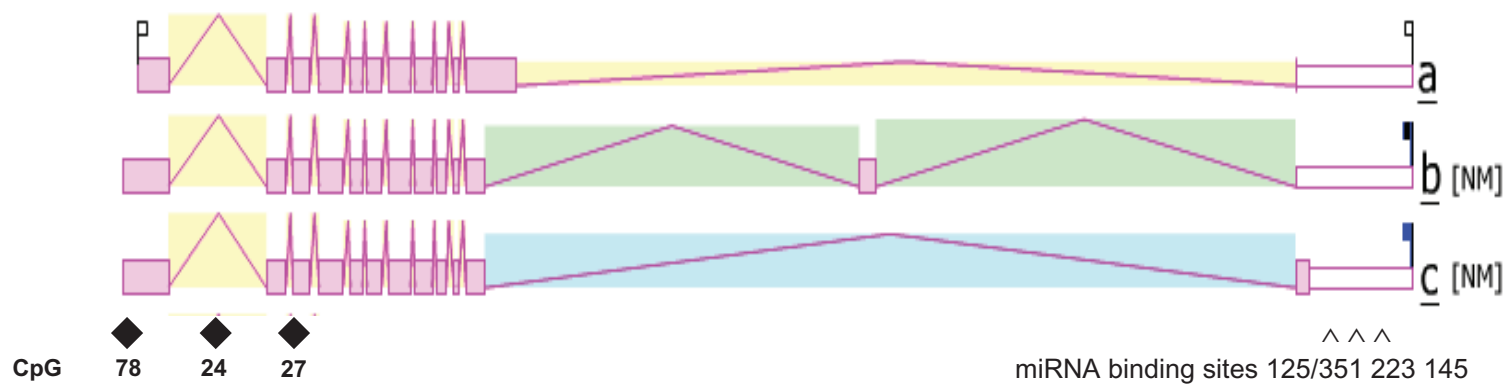

Predicted transcription factor binding sites

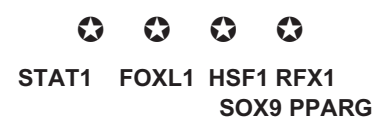

Mouse Scarb1 5' $\rightarrow 3^{\prime}$ 'chromosome 5:125,821,470-125,757,450 size $=64.02 \mathrm{~kb}$

5.1 times average gene expression level

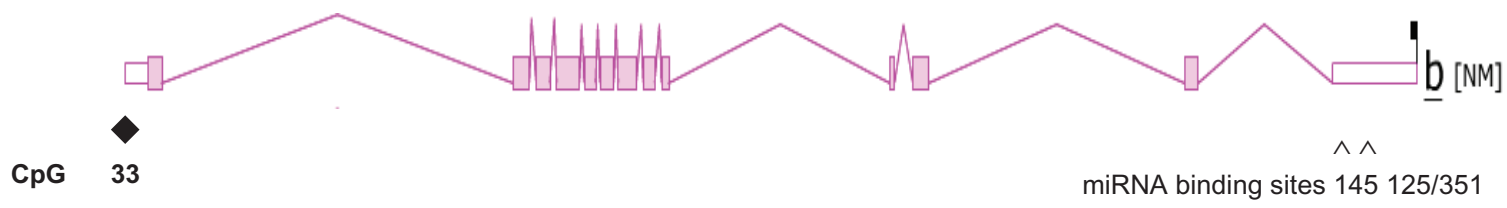

Figure 4 Gene structures and major splicing transcripts for the human and mouse SCARBI genes.

Notes: Derived from the AceView website (http://www.ncbi.nlm.nih.gov/IEB/Research/Acembly/) 31 mature isoform variants are shown with capped 5' and 3' ends for the predicted mRNA sequences; NM refers to the National Center for Biotechnology Information reference sequence; exons are in pink; the directions for transcription are shown as $5^{\prime} \rightarrow 3^{\prime}$; black squares show predicted CPG island sites at or near the $5^{\prime}$ untranslated regions of the genes; the symbol $\wedge$ shows predicted microRNA binding sites observed at or near the SCARBI 3' untranslated regions; sizes of mRNA sequences are shown in kilobases; predicted transcription factor binding sites for human SCARBI are shown as stars.

Abbreviations: SCARBI, scavenger receptor class B type I protein; STATI, signal transducer and activator of transcription; FOXLI, forkhead related transcription factor; HSFI, heat shock transcription factor; RFXI, MHC class II regulatory factor; SOX9, transcription factor; PPARG, peroxisome proliferator-activated receptor $\gamma$; SCARBI, scavenger receptor class $B$ type $I$. 
compared with the $\mathrm{CpG}$ islands within housekeeping gene promoters expressed in most tissues. ${ }^{89}$ Of particular significance among the transcription factor binding sites observed is the peroxisome proliferator-activated receptor- $\gamma$ site, which has been shown to stimulate liver SCARB1 expression ${ }^{90}$ and to participate in regulating cholesterol uptake and efflux from macrophages, and to promote uptake of oxidized low-density lipoproteins and subsequent differentiation of monocytes into foam cells..$^{91-93}$ The prediction of multiple miRNA target sites within the $3^{\prime}$-untranslated regions of human SCARB1 and mouse $S c a r b 1$ is also potentially of major significance because of the role that small noncoding RNAs play in regulating mRNA and protein expression during embryonic development. ${ }^{94}$

\section{Comparative human and mouse SCARBI tissue expression}

Figure 5 presents "heat maps" showing comparative gene expression for various human and mouse tissues obtained from GNF Expression Atlas Data using the U133 A and GNF1H (human) and GNF1M (mouse) chips (http://genome. ucsc.edu; http://biogps.gnf.org). ${ }^{68}$ These data supported a broad and high level of tissue expression for human and mouse SCARB1, particularly for the adrenal gland, liver, lymphocytes, ovary and placenta, which is consistent with previous reports for these genes. ${ }^{1,8,47,74}$ Overall however, human and mouse SCARB1 tissue expression levels were 3-4 times the average level of gene expression, which supports the key role played by this enzyme in lipid metabolism, especially in the liver, adrenal glands, and lymphocytes, and during embryonic development (http://www.ncbi.nlm.nih. gov/IEB/Research/Acembly/). ${ }^{31}$

\section{Phylogeny and divergence of SCARBI and other vertebrate CD36-like sequences}

A phylogenetic tree (Figure 6) was calculated by the progressive alignment of 19 vertebrate SCARB1 amino acid
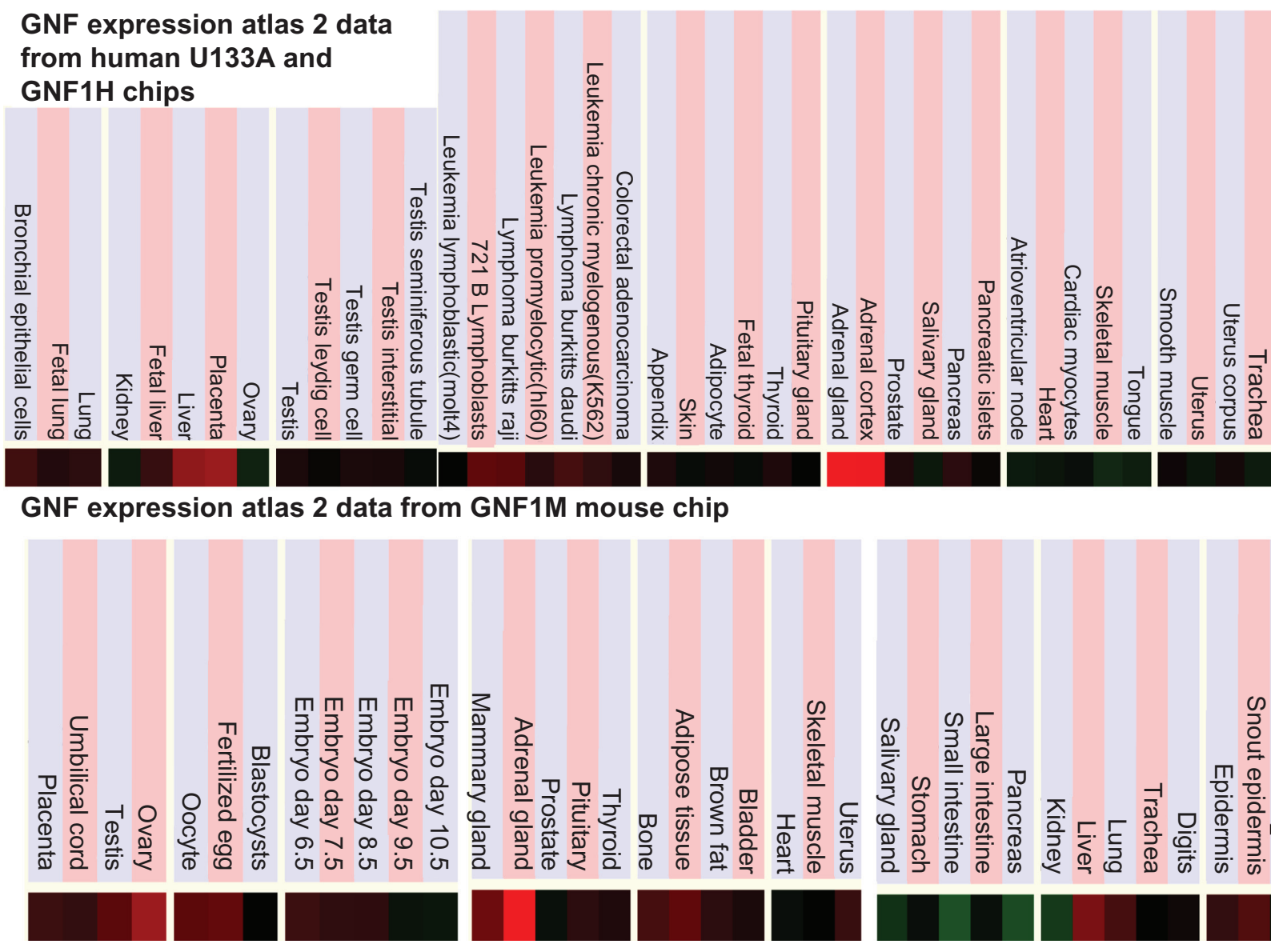

Figure 5 Comparative tissue expression for human and mouse SCARBI genes.

Notes: Expression "heat maps" (GNF Expression Atlas 2 data) (http://biogps.gnf.org) ${ }^{68}$ were examined for comparative gene expression levels among human and mouse tissues for SCARBI genes showing high (red); intermediate (black); and low (green) expression levels. Derived from human and mouse genome browsers (http://genome.ucsc.edu). ${ }^{65}$ Abbreviation: SCARBI, scavenger receptor class B type $I$. 


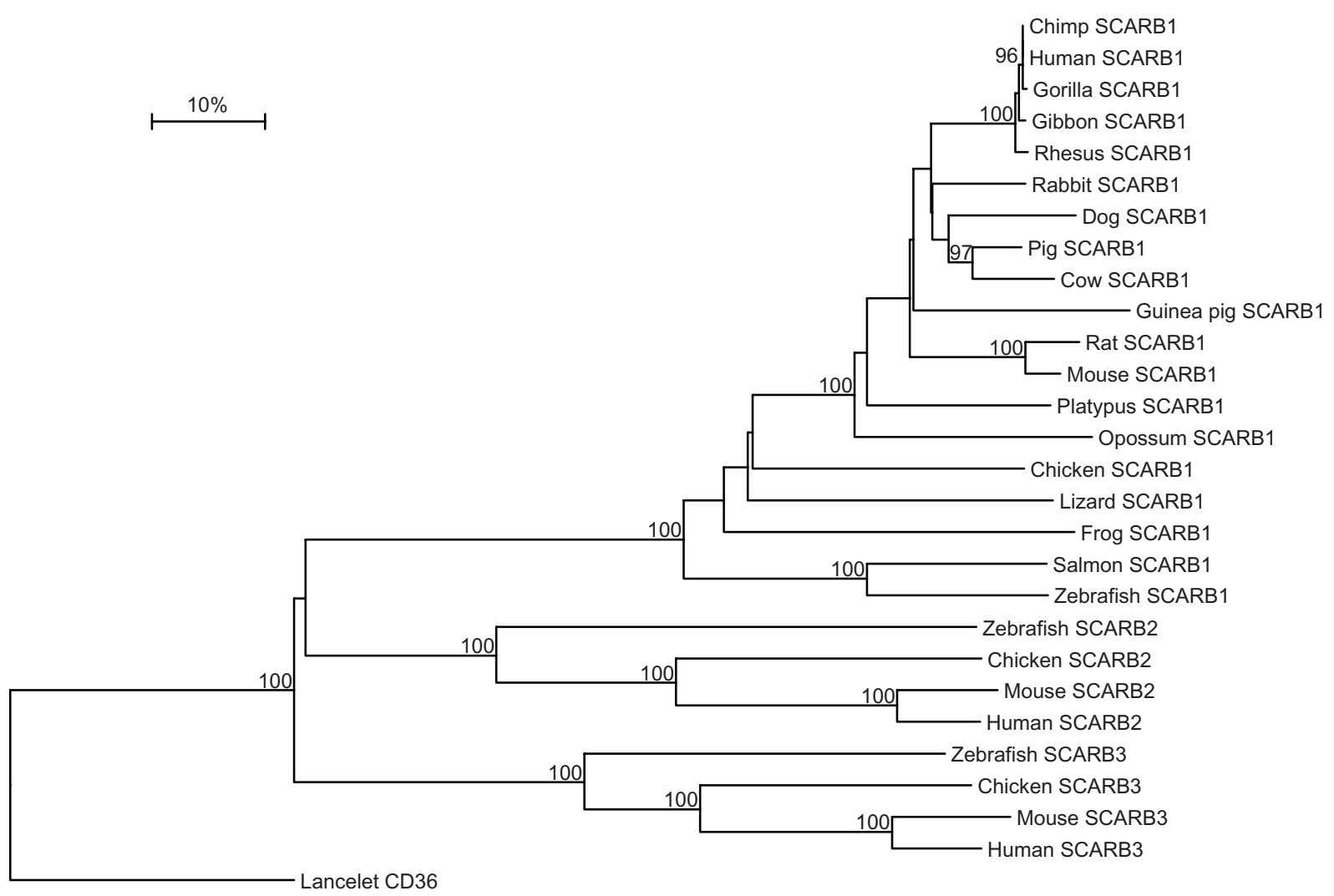

Figure 6 Phylogenetic tree of vertebrate SCARBI amino acid sequences with human, mouse, chicken, and zebrafish SCARB2 and SCARB3 (CD36) sequences.

Notes: The tree is labeled with the SCARB-like name and the name of the animal and is "rooted" with the lancelet CD36 sequence. Note the three major clusters corresponding to the SCARBI, SCARB2, and SCARB3 (CD36) gene families. A genetic distance scale is shown. The number of times a clade (sequences common to a node or branch) occurred in the bootstrap replicates are shown. Only replicate values of 95 or more, which are highly significant, are shown, with 100 bootstrap replicates performed in each case. A proposed sequence of CD36 gene duplication events is shown.

Abbreviation: SCARB, scavenger receptor class B.

sequences with human, mouse, chicken, and zebrafish SCARB2 and SCARB3 (CD36) sequences, which was "rooted" with the lancelet (B. floridae) CD36 sequence (see Table 1). The phylogram showed clustering of the SCARB1 sequences into groups, which was consistent with their evolutionary relatedness as well as groups for human, mouse, chicken, and zebrafish SCARB2 and SCARB3 (CD36) sequences, which was distinct from the lancelet CD36 sequence. These groups were significantly different from each other (with bootstrap values of about 100/100). This is suggestive of a sequence of $C D 36$-like gene duplication events: ancestral CD36 (SCARB3) gene duplication $\rightarrow$ $S C A R B 1$ and $C D 36$ genes; followed by a further $C D 36$ duplication, generating the $S C A R B 2$ and $C D 36$ genes found in all vertebrate species examined (Figure 6). It is apparent from this study of vertebrate CD-like genes and proteins that this is an ancient protein for which a proposed common ancestor for the SCARB1, SCARB2, and SCARB3 (CD36) genes may have predated the appearance of fish more than 500 million years ago. ${ }^{95}$

\section{Conclusion}

The results of the present study indicate that vertebrate SCARB 1 genes and encoded proteins represent a distinct gene and protein family of CD36-like proteins which share key conserved sequences that have been reported for other CD36-like proteins (SCARB2 and SCARB3 [CD36]) previously studied. ${ }^{19-29}$ SCARB1 has a unique property among these proteins in serving as a major receptor for HDL in the body and participating in reverse cholesterol transport. ${ }^{10,33,46,49}$ HDL binding to SCARB1 stimulates endothelial nitric oxide synthase activity, apparently by increasing intracellular ceramide levels, which leads to cholesterol transfer from HDL into the target cell. ${ }^{4,96}$ SCARB1 has also been implicated in the remodeling of large lipoprotein particles by endothelial lipase during SCARB1mediated uptake of HDL cholesterol. ${ }^{97}$ SCARB 1 is encoded by a single gene among the vertebrate genomes studied and is highly expressed in human and mouse tissues, particularly in adrenal glands, liver, lymphocytes, and embryonic tissues, and usually contains 12 coding exons. Predicted secondary 
structures for vertebrate SCARB1 proteins show strong similarities with other CD36-like proteins, SCARB2 and SCARB3 (or CD36). Three major structural domains were apparent for vertebrate SCARB1, including the N-terminal and C-terminal cytoplasmic domain, the N-terminal and C-terminal transmembrane domain, and the exoplasmic domain, containing the "lipid-transfer active" free $\mathrm{SH}$ Cys384, two disulfide bridges, and several N-glycosylation sites for glycan binding. Phylogenetic studies using 19 vertebrate SCARB1 sequences with human, mouse, chicken, and zebrafish SCARB2 and SCARB3 (CD36) sequences indicated that the $S C A R B 1$ gene has appeared early in vertebrate evolution following a gene duplication event of the ancestral CD36 (SCARB3) gene, prior to the appearance of bony fish, more that 500 million years ago.

\section{Acknowledgments}

This project was supported by the National Institutes of Health (grants P01 HL028972 and P51 RR013986). In addition, this investigation was conducted in facilities constructed with support from Research Facilities Improvement Program (Grants 1 C06 RR13556, 1 C06 RR15456, and 1 C06 RR017515). We also acknowledge the expert assistance of Dr Bharet Patel of Griffith University with the phylogeny studies.

\section{Disclosure}

The authors report no conflicts of interest in this work.

\section{References}

1. Acton S, Rigotti A, Landschulz KT, Xu S, Hobbs HH, Krieger M. Identification of scavenger receptor SR-BI as a high density lipoprotein receptor. Science. 1996;271(5248):518-520.

2. Ikemoto M, Arai H, Feng D, et al. Identification of a PDZ-domaincontaining protein that interacts with the scavenger receptor class B type I. Proc Natl Acad Sci U S A. 2000;97(12):6538-6543.

3. Bultel-Brienne S, Lestavel S, Pilon A, et al. Lipid free apolipoprotein E binds to the class B type I scavenger receptor I (SR-BI) and enhances cholesteryl ester uptake from lipoproteins. J Biol Chem. 2002; 277(39):36092-36099.

4. Li XA, Titlow WB, Jackson BA, et al. High density lipoprotein binding to scavenger receptor, Class B, type I activates endothelial nitric-oxide synthase in a ceramide-dependent manner. $J$ Biol Chem. 2002;277(13):11058-11063.

5. Osgood D, Corella D, Demissie S, et al. Genetic variation at the scavenger receptor class B type I gene locus determines plasma lipoprotein concentrations and particle size and interacts with type 2 diabetes: the Framingham study. J Clin Endocrinol Metab. 2003;88(6): 2869-2879.

6. Marsche G, Zimmermann R, Horiuchi S, Tandon NN, Sattler W, Malle E. Class B scavenger receptors CD36 and SR-BI are receptors for hypochlorite-modified low density lipoprotein. J Biol Chem. 2003;278(48):47562-47570.

7. Levy E, Ménard D, Suc I, et al. Ontogeny, immunolocalisation, distribution and function of SR-BI in the human intestine. J Cell Sci. 2004;117(Pt 2):327-337.
8. Connelly MA, Williams DL. Scavenger receptor BI: A scavenger receptor with a mission to transport high density lipoprotein lipids. Curr Opin Lipidol. 2004;15(3):287-295.

9. Out R, Kruijt JK, Rensen PCN, et al. Scavenger receptor BI plays a role in facilitating chylomicron metabolism. $J$ Biol Chem. 2004;279(18):18401-18406.

10. Kent AP, Stylianou IM. Scavenger receptor class B member 1 protein: hepatic regulation and its effects on lipids, reverse cholesterol transport and atherosclerosis. Hepatic Medicine:Evidence and Research. 2011;3:29-44.

11. Scarselli E, Ansuini H, Cerino R, et al. The human scavenger receptor class $\mathrm{B}$ type $\mathrm{I}$ is a novel candidate receptor for the hepatitis $\mathrm{C}$ virus. EMBO J. 2002;21(19):5017-5025.

12. Bartosch B, Vitelli A, Granier C, et al. Cell entry of hepatitis C virus requires a set of co-receptors that include the CD81 tetraspanin and the SR-B1 scavenger receptor. J Biol Chem. 2003;278(43): 41624-41630.

13. Dorner M, Horwitz JA, Robbins JB, et al. A genetically humanized mouse model for hepatitis C virus infection. Nature. 2011;474(7350): $208-211$.

14. Thi DVL, Dreux M, Cosset FL. Scavenger receptor class B type I and the hypervariable region- 1 of hepatitis $\mathrm{C}$ virus in cell entry and neutralisation. Expert Rev Mol Med. 2011;13:e13.

15. Nofer JR, van Eck M. HDL scavenger receptor class B type 1 and platelet function. Curr Opin Lipidol. 2011;22(4):277-282.

16. Kawasaki Y, Nakagawa A, Nagaosa K, Shiratsuchi A, Nakanishi Y. Phosphatidylserine binding of class B scavenger receptor type I, a phagocytosis receptor of testicular Sertoli cells. J Biol Chem. 2002; 277(30):27559-27566.

17. Nishiuchi T, Murao K, Imachi H, et al. Scavenger receptor class BI mediates the anti-apoptotic effect of erythropoietin. Ann Med. 2010; 42(2):151-160.

18. Feng H, Guo L, Wang D, et al. Deficiency of scavenger receptor BI leads to impaired lymphocyte homeostasis and autoimmune disorders in mice. Arterioscler Thromb Vasc Biol. 2011;31(11):2543-2551.

19. Fujita $\mathrm{H}$, Takata $\mathrm{Y}$, Kono $\mathrm{A}$, et al. Isolation and sequencing of a cDNA clone encoding the $85 \mathrm{kDa}$ human lysosomal sialoglycoprotein (hLGP85) in human metastatic pancreas islet tumor cells. Biochem Biophys Res Commun. 1992;184(2):604-611.

20. Ogata S, Fukuda M. Lysosomal targeting of Limp II membrane glycoprotein requires a novel Leu-Ile motif at a particular position in its cytoplasmic tail. J Biol Chem. 1994;269(7):5210-5217.

21. Tabuchi N, Akasaki K, Sasaki T, Kanda N, Tsuji H. Identification and characterization of a major lysosomal membrane glycoprotein, LGP85/ LIMP II in mouse liver. J Biochem. 1997;122(4):756-763.

22. Kuronita T, Eskelinen EL, Fujita H, Saftig P, Himeno M, Tanaka Y. A role for the lysosomal membrane protein LGP85 in the biogenesis and maintenance of endosomal and lysosomal morphology. J Cell Sci. 2002;115(Pt 21):4117-4131.

23. Lin YW, Lin HY, Tsou YL, et al. Human SCARB2-mediated entry and endocytosis of EV71. PLoS One. 2012;7(1):e30507.

24. Simantov R, Silverstein. CD36: a critical anti-angiogenic receptor. Front Biosci. 2003;8:S874-S882.

25. Adachi H, Tsujimoto M. Endothelial scavenger receptors. Prog Lipid Res. 2006;45(5):379-404.

26. Collot-Teixeira S, Martin J, McDermott-Roe C, Poston R, McGregor JL. CD36 and macrophages in atherosclerosis. Cardiovasc Res. 2007;75(3):468-477.

27. Martin CA, Longman E, Wooding C, et al. CD36, a class B scavenger receptor, functions as a monomer to bind acetylated and oxidized lowdensity lipoproteins. Protein Sci. 2007;16(11):2531-2541.

28. Gautam S, Banerjee M. The macrophage Ox-LDL receptor, CD36 and its association with type II diabetes mellitus. Mol Genet Metab. 2011; 102(4):389-398.

29. Ren Y. Peroxisome proliferator-activator receptor $\gamma$ : a link between macrophage CD36 and inflammation in malaria infection. PPAR Res. 2012;2012:640769. 
30. McLean MP, Sandhoff TW. Expression and hormonal regulation of the high-density lipoprotein (HDL) receptor scavenger receptor class B type I messenger ribonucleic acid in the rat ovary. Endocrine. 1998;9(3):243-252.

31. Thierry-Mieg D, Thierry-Mieg J. AceView: A comprehensive cDNAsupported gene and transcripts annotation. Genome Biol. 2006;7 Suppl 1: S12.1-S12.14.

32. Van Eck M, Twisk J, Hoekstra M, et al. Differential effects of scavenger receptor BI deficiency on lipid metabolism in cells of the arterial wall and in the liver. J Biol Chem. 2003;278(26):23699-23705.

33. Vergeer M, Korporaal SJ, Franssen R, et al. Genetic variant of the scavenger receptor BI in humans. N Engl J Med. 2011;364(2):136-145.

34. Tai ES, Adiconis X, Ordovas JM, et al. Polymorphisms at the SRBI locus are associated with lipoprotein levels in subjects with heterozygous familial hypercholesterolemia. Clin Genet. 2003;63(1):53-58.

35. Roberts CG, Shen H, Mitchell BD, Damcott CM, Shuldiner AR, Rodriguez A. Variants in scavenger receptor class B type I gene are associated with HDL cholesterol levels in younger women. Hum Hered. 2007;64(2):107-111.

36. Liu Y, Ordovas JM, Gao G, et al. The SCARB1 gene is associated with lipid response to dietary and pharmacological interventions. J Hum Genet. 2008;53(8):709-717.

37. Cerda Á, Genvigir FD, Rodrigues AC, et al. Influence of polymorphisms and cholesterol-lowering treatment on SCARB1 mRNA expression. J Atheroscler Thromb. 2011;18(8):640-651.

38. Acton S, Osgood D, Donoghue M, et al. Association of polymorphisms at the SR-BI gene locus with plasma lipid levels and body mass index in a white population. Arterioscler Thromb Vasc Biol. 1999;19(7):1734-1743.

39. Constantineau J, Greason E, West M, et al. A synonymous variant in scavenger receptor, class B, type I gene is associated with lower SR-BI protein expression and function. Atherosclerosis. 2010; 210(1):177-182.

40. Pérez-Martínez P, Pérez-Jiménez F, Bellido C, et al. A polymorphism exon 1 variant at the locus of the scavenger receptor class B type I (SCARB1) gene is associated with differences in insulin sensitivity in healthy people during the consumption of an olive oil-rich diet. J Clin Endocrinol Metab. 2005;90(4):2297-3000.

41. Ritsch A, Sonderegger G, Sandhofer A, et al. Scavenger receptor class B type I polymorphisms and peripheral arterial disease. Metabolism. 2007;56(8):1135-1141

42. Rodrigues CD, Hannus M, Prudêncio M, et al. Host scavenger receptor SR-BI plays a dual role in the establishment of malaria parasite liver infection. Cell Host Microbe. 2008;4(3):271-278.

43. Gerhard DS, Wagner L, Feingold EA, et al; MGC Project Team. The status, quality, and expansion of the NIH full-length cDNA project: the Mammalian Gene Collection (MGC). Genome Res. 2004; 14(10B):2121-2127.

44. Zhang X, Merkler KA, McLean MP. Characterization of regulatory intronic and exonic sequences involved in alternative splicing of scavenger receptor class B gene. Biochem Biophys Res Commun. 2008;372(1):173-178.

45. Welch CL, Xia YR, Gu LJ, et al. Srb1 maps to mouse chromosome 5 in a region harboring putative QTLs for plasma lipoprotein levels. Mamm Genome. 1997;8(12):942-944.

46. Johnson MS, Svensson PA, Helou K, et al. Characterization and chromosomal localization of rat scavenger receptor class B type I, a high density lipoprotein receptor with a putative leucine zipper domain and peroxisomal targeting sequence. Endocrinology. 1998;139(1):72-80.

47. Rajapaksha WR, McBride M, Robertson L, O'Shaughnessy PJ. Sequence of the bovine HDL-receptor (SR-BI) cDNA and changes in receptor mRNA expression during granulosa cell luteinization in vivo and in vitro. Mol Cell Endocrinol. 1997;134(1):59-67.

48. Sundvold H, Helgeland H, Baranski M, Omholt SW, Våge DI. Characterisation of a novel paralog of scavenger receptor class B member I (SCARB1) in Atlantic salmon (Salmo salar). BMC Genet. 2011;12:52.
49. Webb NR, Connell PM, Graf GA, et al. SR-BII, an isoform of the scavenger receptor BI containing an alternate cytoplasmic tail, mediates lipid transfer between high density lipoprotein and cells. J Biol Chem. 1998;273(24):15241-15248.

50. Eckhardt ER, Cai L, Shetty S, et al. High density lipoprotein endocytosis by scavenger receptor SR-BII is clathrin-dependent and requires a carboxyl-terminal dileucine motif. $J$ Biol Chem. 2006;281(7):4348-4353.

51. Naj AC, West M, Rich SS, et al. Association of scavenger receptor class B type I polymorphisms with subclinical atherosclerosis: the Multi-Ethnic Study of Atherosclerosis. Circ Cardiovasc Genet. 2010;3(1):47-52.

52. Altschul F, Vyas V, Cornfield A, et al. Basic local alignment search tool. J Mol Biol. 1990;215(3):403-410.

53. Lander ES, Linton LM, Birren B, et al; International Human Genome Sequencing Consortium. Initial sequencing and analysis of the human genome. Nature. 2001;409(6822):860-921.

54. Chimpanzee Sequencing and Analysis Consortium. Initial sequence of the chimpanzee genome and comparison with the human genome. Nature. 2005;437(7055):69-87.

55. Gibbs RA, Rogers J, Katze MG, et al. Evolutionary and biomedical insights from the rhesus macaque genome. Science. 2007; 316(5822):222-234.

56. Elsik CG, Tellam RL, Worley KC, et al; Bovine Genome Sequencing and Analysis Consortium. The genome sequence of taurine cattle: a window to ruminant biology and evolution. Science. 2009; 324(5926):522-528.

57. Waterston RH, Lindblad-Toh K, Birney E, et al; Mouse Genome Sequencing Consortium. Initial sequencing and comparative analysis of the mouse genome. Nature. 2002;420(6915):520-562.

58. Gibbs RA, Weinstock GM, Metzker ML; Rat Genome Sequencing Project Consortium. Genome sequence of the Brown Norway rat yields insights into mammalian evolution. Nature. 2004;428(6982): 493-521.

59. Mikkelsen TS, Wakefield MJ, Aken B, et al. Genome of the marsupial Monodelphis domestica reveals innovation in noncoding sequences. Nature. 2007;447(7141):167-175.

60. Warren WC, Hillier LW, Marshall Graves JA, et al. Genome analysis of the platypus reveals unique signatures of evolution. Nature. 2008;453(7192):175-183.

61. International Chicken Genome Sequencing Consortium. Sequence and comparative analysis of the chicken genome provide unique perspectives on vertebrate evolution. Nature. 2004;432(7018):695-716.

62. Eckalbar WL, Lasku E, Infante CR, et al. Somitogenesis in the anole lizard and alligator reveals evolutionary convergence and divergence in the amniote segmentation clock. Dev Biol. 2012;363(1): 308-319.

63. Hellsten U, Harland RM, Gilchrist MJ, et al. The genome of the western clawed frog Xenopus tropicalis. Science. 2010;328(5978):633-636.

64. Sprague J, Bayraktaroglu L, Clements D, et al. The zebrafish information network: the zebrafish model organism database. Nucleic Acids Res. 2006;34(Database Issue):D581-D585.

65. Kent WJ, Sugnet CW, Furey TS, et al. The human genome browser at UCSC. Genome Res. 2002;12(6):994-1006.

66. McGuffin LJ, Bryson K, Jones DT. The PSIPRED protein structure prediction server. Bioinformatics. 2000;16(4):404-405.

67. Gupta R, Brunak S. Prediction of glycosylation across the human proteome and the correlation to protein function. Pac Symp Biocomput. 2002; 7:310-322.

68. Su AI, Wiltshire T, Batalov S, et al. A gene atlas of the human and mouse protein encoding transcriptomes. Proc Natl Acad Sci U S A. 2004;101(16):6062-6067.

69. Hall TA. BioEdit: a user-friendly biological sequence alignment editor and analysis program for Windows 95/98/NT. Nucleic Acids Symp Ser. 1999;41:95-99.

70. Kimura M. The Neutral Theory of Molecular Evolution. Cambridge, UK: Cambridge University Press; 1983. 
71. Van De Peer Y, de Wachter R. TreeCon for Windows: a software package for the construction and drawing of evolutionary trees for the Microsoft Windows environment. Comput Appl Sci. 1994;10(5):569-575.

72. Saitou N, Nei M. The neighbour-joining method: a new method for reconstructing phylogenetic trees. Mol Biol Evol. 1987;4(4):406-411.

73. Felsenstein J. Confidence limits on phylogenies: an approach using the bootstrap. Evolution. 1985;39:783-791.

74. Calvo D, Vega MA. Identification, primary structure, and distribution of CLA-1, a novel member of the CD36/LIMPII gene family. $J$ Biol Chem. 1993;268(25):18929-18935.

75. Silver DL. A carboxyl-terminal PDZ-interacting domain of scavenger receptor B, Type I is essential for cell surface expression in liver. J Biol Chem. 2002;277(37):34042-34047.

76. Gaidukov L, Nager AR, Xu S, Penman M, Krieger M. Glycine dimerization motif in the N-terminal transmembrane domain of the high density lipoprotein receptor SR-BI required for normal receptor oligomerization and lipid transport. J Biol Chem. 2011;286(21):18452-18464.

77. Yua M, Romer KA, Nieland TJ, et al. Exoplasmic cysteine Cys384 of the HDL receptor SR-BI is critical for its sensitivity to a small-molecule inhibitor and normal lipid transport activity. Proc Natl Acad Sci USA. 2011;108(30):12243-12248.

78. Papale GA, Hanson PJ, Sahoo D. Extracellular disulfide bonds support scavenger receptor class B type I-mediated cholesterol transport. Biochemistry. 2011;50(28):6245-6254.

79. Chen R, Jiang X, Sun D, et al. Glycoproteomics analysis of human liver tissue by combination of multiple enzyme digestion and hydrazide chemistry. J Proteome Res. 2009:8(2):651-661.

80. Junyent M, Arnett DK, Tsai MY, et al. Genetic variants at the PDZinteracting domain of the scavenger receptor class B type I interact with diet to influence the risk of metabolic syndrome in obese men and women. J Nutr. 2009;139(5):842-848.

81. Kocher O, Birrane G, Yesilaltay A, et al. Identification of the PDZ3 domain of the adaptor protein PDZK1 as a second, physiologically functional binding site for the $\mathrm{C}$ terminus of the high density lipoprotein receptor scavenger receptor class B type I. J Biol Chem. 2011;286(28):25171-25186

82. Ranganathan R, Ross EM. PDZ domain proteins: Scaffolds for signaling complexes. Curr Biol. 1997;7(12):R770-R773.

83. Lee H-J, Zheng JI. PDZ domains and their binding partners: structure, specificity, and modification. Cell Commun Signal. 2010;8:8.
84. MacArthur MW, Thornton JM. Influence of proline residues on protein conformation. J Mol Biol. 1991;218(2):397-412.

85. Slepkov ER, Rainey JK, Sykes BD, Fliegel L. Structural and functional analysis of the $\mathrm{Na}^{+} / \mathrm{H}^{+}$exchanger. Biochem J. 2007;401(3):623-633.

86. Kay BK, Williamson MP, Sudol M. The importance of being proline: the interaction of proline-rich motifs in signaling proteins with their cognate domains. FASEB J. 2000;14(2):231-241.

87. Coleman MD, Bass RB, Mehan RS, Falke JJ. Conserved glycine residues in the cytoplasmic domain of the aspartate receptor play essential roles in kinase coupling and on-off switching. Biochem. 2005;44(21):7687-7695.

88. Krieger, A Möglich A, Kiefhaber T. Effect of proline and glycine residues on dynamics and barriers of loop formation in polypeptide $\mathrm{F}$. J Am Chem Soc. 2005;127(10):3346-3352.

89. Saxonov S, Berg P, Brutlag DL. A genome-wide analysis of $\mathrm{CpG}$ dinucleotides in the human genome distinguishes two distinct classes of promoters. Proc Natl Acad Sci U S A. 2006;103(10):1412-1417.

90. Malerød L, Sporstøl M, Juvet LK, Mousavi A, Gjøen T, Berg T. Hepatic scavenger receptor class B, type I is stimulated by peroxisome proliferator-activated receptor gamma and hepatocyte nuclear factor 4alpha. Biochem Biophys Res Commun. 2003;305(3):557-565.

91. Merkel M, Eckel RH, Goldberg IJ. Lipoprotein lipase: genetics, lipid uptake, and regulation. J Lipid Res. 2002;43(12):1997-2006.

92. SteinY, Stein O. Lipoprotein lipase and atherosclerosis. Atherosclerosis. 2003;170(1):1-9.

93. Ashok-Kumar M, Subhashini NGV, Kanthimathi S, et al. Associations for lipoprotein lipase and peroxisome proliferator-activated receptor- $\gamma$ gene and coronary heart disease in an Indian population. Arch Med Res. 2010;41(1):19-25.

94. Stefani G, Slack FJ. Small non-coding RNAs in animal development Nat Rev Mol Cell Biol. 2008;9(3):219-230.

95. Donoghue PCJ, Benton MJ. Rocks and clocks: calibrating the tree of life using fossils and molecules. Trends Ecol Evol. 2007;22(8):424-431.

96. Assanasen C, Mineo C, Seetharam D, et al Cholesterol binding, efflux, and a PDZ-interacting domain of scavenger receptor-BI mediate HDLinitiated signaling. J Clin Invest. 2005;115(4):969-977.

97. Nijstad N, Wiersma H, Gautier T, van der Giet M, Maugeais C, Tietge UJ. Scavenger receptor BI-mediated selective uptake is required for the remodeling of high density lipoprotein by endothelial lipase. J Biol Chem. 2009;284(10):6093-6100. 


\section{Supplementary figure}

conserved glycines involved in dimerisation * $* 20$
Mouse
Rat

$\mid \leftarrow$ cytoplasmic $\rightarrow \mid \leftarrow \quad$ transmembrane $\quad \rightarrow \mid \leftarrow \alpha 1$ exoplasmic $\rightarrow$

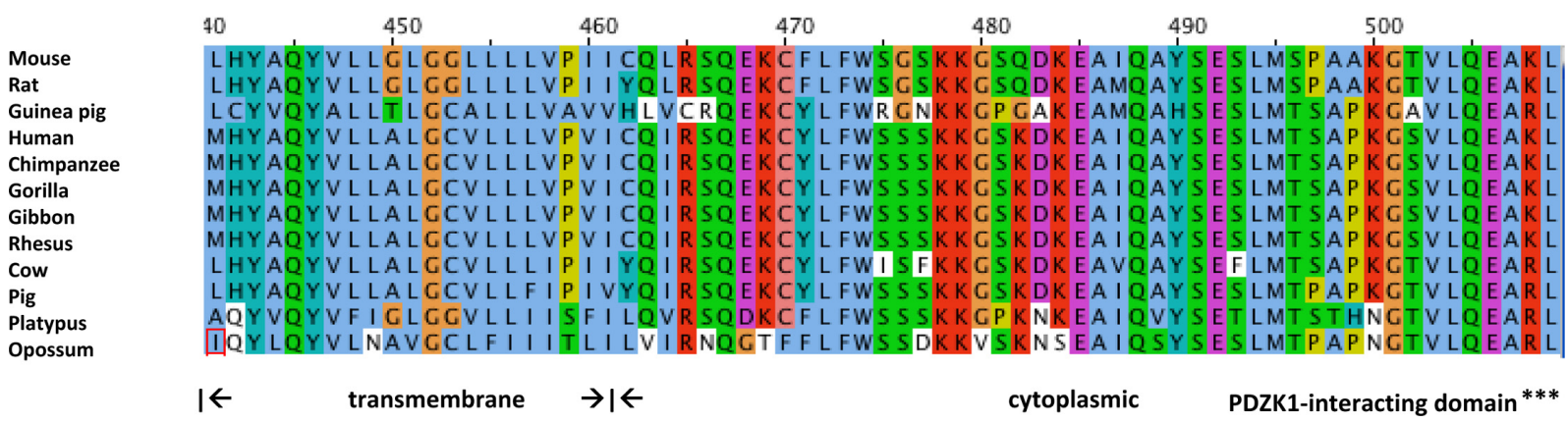

Figure SI Amino acid sequence alignments for mammalian SCARBI N-terminal and C-terminal sequences.

Notes: Amino acids are color-coded: yellow for proline (P); S (serine); green for hydrophilic amino acids, S (serine), Q (glutamine), N (asparagine), and T (threonine); brown for glycine (G); light blue for hydrophobic amino acids, L (leucine), I (isoleucine), V (valine), M (methionine), W (tryptophan); dark blue for amino acids, T (tyrosine) and H (histidine); purple for acidic amino acids, E (glutamate) and D (aspartate); and red for basic amino acids, K (lysine) and R (arginine); conserved $\mathrm{N}$-terminal glycines are shown as*; the last three C-terminal amino acids (PDZKI-interacting zone) are also shown as*.

Abbreviation: SCARBI, scavenger receptor class B type I.

\section{Publish your work in this journal}

Research and Reports in Biochemistry is an international, peer-reviewed, open access journal publishing original research, reports, reviews and commentaries on all areas of biochemistry. The manuscript management system is completely online and includes a very quick and fair peer-review system. Visit http://www.dovepress.com/testimonials.php to read real quotes from published authors. 